\title{
Thermogravimetric method for determination of oxygen stoichiometry in superconducting $1: 2: 3$ and metal-substituted $1: 2: 3$ compounds
}

\author{
R VENKATARAMANI, S P GARG and S MAZUMDER* \\ Physical Metallurgy Division, "Neutron Physics Division, Bhabha Atomic Research \\ Centre, Bombay 400085 , India
}

\begin{abstract}
The paper presents a modified thermogravimetric method for determination of oxygen stoichiometry of the oxide superconductors $\mathrm{YBa}_{2} \mathrm{Cu}_{3} \mathrm{O}_{7-\delta}$ and metal-substituted compounds of the type $\mathrm{YBa}_{2-x} \mathrm{La}_{x} \mathrm{Cu}_{3} \mathrm{O}_{7+\delta}$ and $\mathrm{YBa}_{2}\left(\mathrm{Cu}_{1-x} \mathrm{M}_{x}\right)_{3} \mathrm{O}_{7-\delta}(\mathrm{M}=\mathrm{Mg} / \mathrm{Zn})$ between $25^{\circ}$ and $930^{\circ} \mathrm{C}$.
\end{abstract}

Keywords. Thermogravimetry; stoichiometry.

\section{Introduction}

The role of copper and oxygen is of considerable importance in the 1:2:3 oxide superconductor. It is generally accepted that deviation of oxygen stoichiometry from an ideal value of 7 either way adversely affects the superconductivity of the material (Mazumder et al 1988). Efforts have been made earlier (Mazumder et al 1988; Segre et al 1987; Sunshine et al 1987) to raise the oxygen stoichiometry beyond 7 by partially replacing the bivalent $\mathrm{Ba}$ with trivalent La. Similarly, partial substitution of $\mathrm{Cu}$ by bivalent metals like $\mathrm{Mg} / \mathrm{Zn}$ or trivalent metals like $\mathrm{Al} / \mathrm{Ga}$ has also been investigated (Maeno et al 1987; Xiao et al 1988a, b; Singh et al 1988; Kajitani et al 1988). A precise knowledge of oxygen stoichiometry of these oxides is of considerable importance in understanding the superconducting behaviour.

Thermogravimetric analysis (TGA) involving hydrogen reduction has been commonly employed for determination of oxygen stoichiometry. These oxides, however, invariably absorb gases (mainly moisture and $\mathrm{CO}_{2}$ ) and contain residual volatile impurities which cause errors in TGA. In this paper a modified method of TGA is presented.

\section{Experimental}

The superconducting oxide compounds of the type $\mathrm{YBa}_{2} \mathrm{Cu}_{3} \mathrm{O}_{7-\delta}, \mathrm{YBa}_{2-x} \mathrm{La}_{x} \mathrm{Cu}_{3} \mathrm{O}_{7+\delta}$ and $\mathrm{YBa}_{2}\left(\mathrm{Cu}_{1-x} \mathrm{M}_{x}\right)_{3} \mathrm{O}_{7-\delta}(\mathrm{M}=\mathrm{Mg} / \mathrm{Zn})$ were prepared following the solid-state reaction route (Mazumder et al 1988; Garg et al 1989). The sample ( $400 \mathrm{mg}$ ) was charged in a Mettler's thermoanalyser. The charge was heated under a flow $\left(200 \mathrm{ml} / \mathrm{min}\right.$ ) of pure oxygen, at $10^{\circ} \mathrm{C} / \mathrm{min}$ up to $930^{\circ} \mathrm{C}$ for a sufficiently long period $(\sim 1.5 \mathrm{~h})$ until a constant mass of the sample was attained. The charge was then slowly cooled, at $1^{\circ} \mathrm{C} / \mathrm{min}$, to $25^{\circ} \mathrm{C}$. A typical thermogram for $\mathrm{YBa}_{2} \mathrm{Cu}_{2 \cdot 82} \mathrm{Zn}_{0.18} \mathrm{O}_{7-\delta}$ is shown in figure 1 .

The above mentioned treatment removed all absorbed gases, moisture, volatile impurities and undecomposed carbonates and gave an oxide sample well characterized with respect to $T_{c}$ crystal structure and oxygen stoichiometry. The sample 


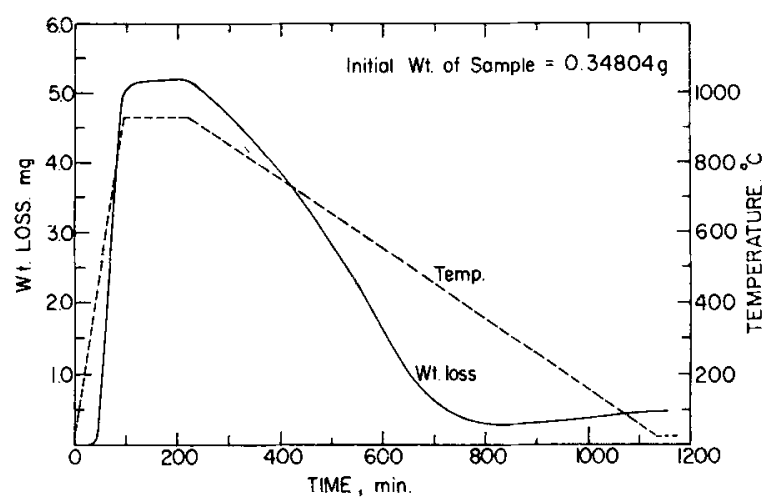

Figure 1. Change in weight of oxide $\mathrm{YBa}_{2} \mathrm{Cu}_{2 \cdot 82} \mathrm{Zn}_{0 \cdot 18} \mathrm{O}_{7-\delta}$ during heating under flow of oxygen.

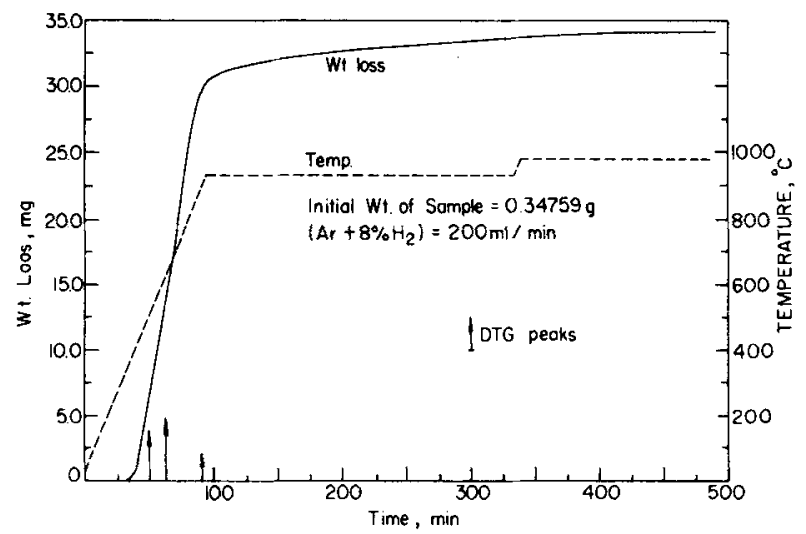

Figure 2. Change in weight of oxide, $\mathrm{YBa}_{2} \mathrm{Cu}_{2 \cdot 82} \mathrm{Zn}_{0 \cdot 18} \mathrm{O}_{7-\delta}$ during reduction under $\left(\mathrm{Ar}+8 \% \mathrm{H}_{2}\right)$ flow.

was then reduced by hydrogen without exposing the charge to atmosphere by replacing oxygen with $\mathrm{Ar}+8 \% \mathrm{H}_{2}$ gas mixture in the thermoanalyser. The use of this gas mixture minimizes errors due to buoyancy effect. The temperature of the sample was increased, under a flow $(200 \mathrm{ml} / \mathrm{min})$ of $\mathrm{Ar}+\mathrm{H}_{2}$ gas mixture, at $10^{\prime \prime} \mathrm{C} / \mathrm{min}$ up to $930^{\circ} \mathrm{C}$ and kept at this temperature for sufficient time till a constant weight was attained. The $\mathrm{Cu}$ contents reduced to metallic state at about $900^{\circ} \mathrm{C}$ in all these oxide compounds. However, in the case of $\mathrm{Zn}$-substituted oxide compound, the sample continued to lose weight even after holding for more than $4 \mathrm{~h}$ at $920^{\circ} \mathrm{C}$ due to vaporization loss of $\mathrm{Zn}$ ( $\mathrm{Zn}$ contents also reduced to the metallic state). The reduction temperature in such cases was raised to $980^{\circ} \mathrm{C}$ to enhance the rate of vaporization loss. The temperature was limited to $980^{\circ} \mathrm{C}$ to avoid melting of the reduced product. The sample attained a constant weight at $980^{\circ} \mathrm{C}$ within $1.5 \mathrm{~h}$ (figure 2) indicating complete removal of $\mathrm{Zn}$ from the charge. This was confirmed by spectrographic 
analysis of the reduced product which gave $\mathrm{Zn}$ content as $<50 \mathrm{ppm}$. It is, therefore, possible to establish composition of the reduced product by this approach.

\section{Results and discussion}

The overall reduction reactions for $1: 2: 3$ superconducting oxide and metal-substituted compounds are given below:

$$
\begin{aligned}
& \mathrm{YBa}_{2} \mathrm{Cu}_{3} \mathrm{O}_{7-\delta}+(3 \cdot 5-\delta) \mathrm{H}_{2} \longrightarrow \\
& 0 \cdot 5 \mathrm{Y}_{2} \mathrm{O}_{3}+2 \mathrm{BaO}+3 \mathrm{Cu}+(3 \cdot 5-\delta) \mathrm{H}_{2} \mathrm{O} \\
& \mathrm{YBa}_{2-x} \mathrm{La}_{x} \mathrm{Cu}_{3} \mathrm{O}_{7+\delta}+(3 \cdot 5+\delta-x / 2) \mathrm{H}_{2} \longrightarrow \\
& 0 \cdot 5 \mathrm{Y}_{2} \mathrm{O}_{3}+(2-x) \mathrm{BaO}+x / 2 \mathrm{La}_{2} \mathrm{O}_{3}+3 \mathrm{Cu}+(3 \cdot 5+\delta-x / 2) \mathrm{H}_{2} \mathrm{O} \\
& \mathrm{YBa}_{2}\left(\mathrm{Cu}_{1-x} \mathrm{Mg}_{x}\right)_{3} \mathrm{O}_{7-\delta}+(3 \cdot 5-\delta-3 x) \mathrm{H}_{2} \longrightarrow \\
& 0 \cdot 5 \mathrm{Y}_{2} \mathrm{O}_{3}+2 \mathrm{BaO}+3(1-x) \mathrm{Cu}+3 x \mathrm{MgO}+(3 \cdot 5-\delta-3 x) \mathrm{H}_{2} \mathrm{O}, \\
& \mathrm{YBa}_{2}\left(\mathrm{Cu}_{1-x} \mathrm{Zn}_{x}\right)_{3} \mathrm{O}_{7-\delta}+(3 \cdot 5-\delta) \mathrm{H}_{2} \longrightarrow \\
& 0 \cdot 5 \mathrm{Y}_{2} \mathrm{O}_{3}+2 \mathrm{BaO}+3(1-x) \mathrm{Cu}+3 x \mathrm{Zn}_{(\mathrm{g})}+(3 \cdot 5-\delta) \mathrm{H}_{2} \mathrm{O} .
\end{aligned}
$$

The mass balance during these reactions gives the following equations:

For reac. 1: $(7-\delta)=3.5+L /(W-L) \times M p / 16$,

For reac. 2: $(7+\delta)=(3 \cdot 5+x / 2)+L /(W-L) \times M p / 16$,

For reac. 3: $\quad(7-\delta)=(3 \cdot 5+3 x)+L /(W-L) \times M p / 16$,

For reac. $4: \quad(7-\delta)=3 \cdot 5-12 \cdot 26 x+L /(W-L) \times M p / 16$,

where $W, L$ and $M p$ are respectively the weight of the characterized sample at $25^{\circ} \mathrm{C}$, overall weight loss during the reduction and molecular weight of the reduced product. Equations (5)-(8) were used to calculate the $(7-\delta$ or $7+\delta)$ values at $25^{\circ} \mathrm{C}$ for the different oxides.

The oxygen stoichiometry at different temperatures was determined from the oxide composition at $25^{\circ} \mathrm{C}$ and the thermogram obtained during cooling of the sample from $930^{\circ} \mathrm{C}$ to $25^{\circ} \mathrm{C}$ at $1^{\circ} \mathrm{C} / \mathrm{min}$ in pure oxygen (figure 1). The rate of cooling $\left(1^{\circ} \mathrm{C} / \mathrm{min}\right) 930^{\circ}$ to $25^{\circ} \mathrm{C}$ keeps the oxide sample always under equilibrium with oxygen. The weight of the sample at any temperature during cooling, therefore, corresponds to the equilibrium $(7-\delta \text { or } 7+\delta)_{T}$ value. These values were calculated using the following equation:

$$
(7-\delta \text { or } 7+\delta)_{T}=(7-\delta \text { or } 7+\delta)_{25}-(M w / 16 W),
$$

where $(7-\delta \text { or } 7+\delta)_{T},(7-\delta \text { or } 7+\delta)_{25}, M, w$ and $W$ are respectively the oxygen stoichiometry at $T$, oxygen stoichiometry at $25^{\circ} \mathrm{C}$, molecular weight of the characterized oxide at $25^{\circ} \mathrm{C}$, weight loss at temperature $t$ and weight of the characterized oxide at $25^{\circ} \mathrm{C}$. The measured $(7-\delta \text { or } 7+\delta)_{T}$ values for different oxides are shown in figure 3 . The correlation between the oxygen stoichiometry, structural and superconducting properties of these oxides has been discussed elsewhere (Segre et al 1987; Sunshine et al 1987; Maeno et al 1987; Xiao et al 1988a, b; Mazumder et al 1988; Singh et al 1988; Kajitani et al 1988). 


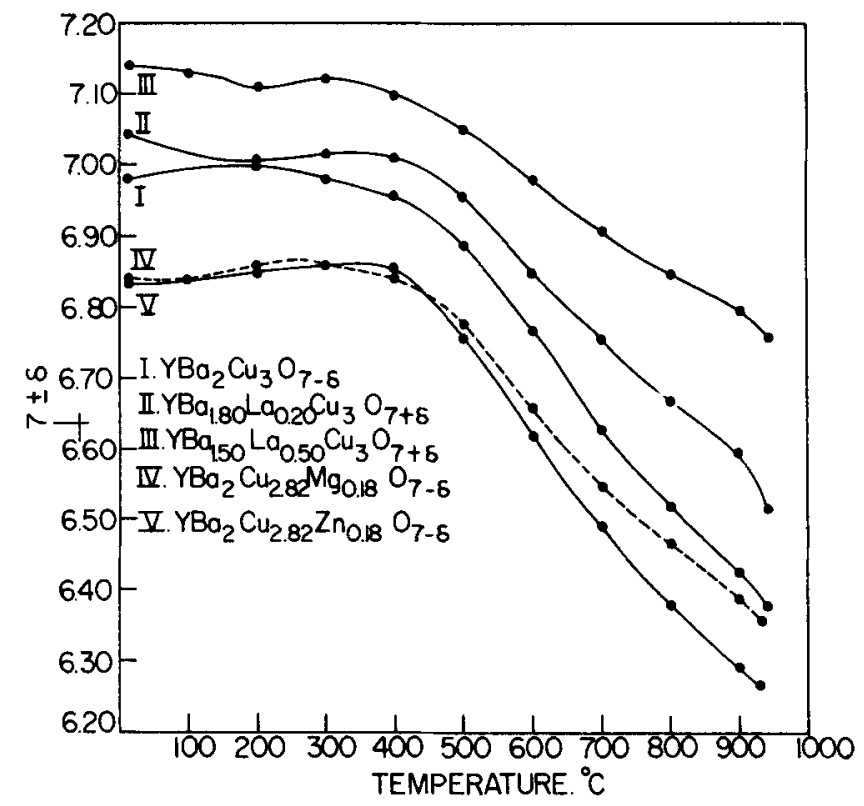

Figure 3. Oxygen stoichiometry $(7 \pm \delta)$ determined as a function of temperature $\left({ }^{\circ} \mathrm{C}\right)$ in oxide superconductors.

\section{Conclusion}

A simple but reliable thermogravimetric method has been established for determination of oxygen stoichiometry in $1: 2: 3$ and metal substituted $1: 2: 3$ oxide superconductors.

\section{References}

Garg S P, Venkataramani R and Mazumder S 1989 Mater. Res. Bull. 24803

Kajitani T, Kusaba K, Kikuchi M, Syono Y and Hirabayashi M 1988 Jpn. J. Appl. Phys. 27 L354

Maeno Y, Tomita T, Kyogoku M, Awaji S, Aoki Y, Hoshino K, Minomi A and Fujita J 1987 Nature (London) 320512

Mazumder S, Rajgopal H, Sequeira A, Venkataramani R, Garg S P, Rajarajan A K, Gupta L C and Vijayaraghavan R 1988 J. Phys. 215967

Segre C U, Dabrowski B, Hinks D G, Zhang K, Jorgensen J D, Beno M A and Schuller I K 1987 Nature (London) 329227

Singh J, Rajarajan A K, Gupta L C and Vijayaraghavan R 1988 in Proc. Solid State Physics, Symp., Bhopal, p. 172

Sunshine S A, Schneemeyer L F, Waszezak J V, Murphy D W, Miraglia S, Santoro A and Beech F 1987 J. Cryst. Growth 85632

Xiao G, Cieplak M Z, Musser D, Gavrin A, Chien C L, Rhyne J J and Gotass J A 1988a Nature (London) 322238

Xiao G, Cieplak M Z, Gavrin A, Streitz F H, Bakhshai A and Chien C L 1988b Phys. Rev. Lett. 601446 